\title{
Treatment of Palm oil mill effluent using activated biochar obtained from the residue of the gasifier
}

\author{
Asadullah $^{\mathrm{a}}$, Dinithi Warnasurya ${ }^{\mathrm{a}}$, P.G.Rthnasiri a, Syed Kamran Sami ${ }^{\mathrm{b}}$, Fahim Ahmed Ibupoto ${ }^{\mathrm{b}}$, \\ Zahid Naeem Qaisrani ${ }^{\mathrm{c}}$, Syed Haseeb Sultan ${ }^{\mathrm{c}}$,Syed Zameer ul Hassan ${ }^{\mathrm{d}}$, Ali Asghar ${ }^{\mathrm{e}}$, Anila Ali ${ }^{\mathrm{e}}$ \\ ${ }^{a}$ University of Moratuwa, Katubeda, Sri Lanka \\ b Sungkyunkwan University (SKKU), Suwon, 16419, Korea \\ ${ }^{c}$ Prince of Songkla University, Thailand \\ d Technical University of Librec, Czech Republic \\ e University Technology Mara, Malysia \\ "Corresponding author's email: asad1562000@yahoo.com
}

\begin{abstract}
Biomass based energy conversion systems at different scale produce heat, power, fuels and other by-products which can be used to meet the requirements of domestic and industrial applications. Using different biomass feed stocks; many useful by-products such as bio char can be obtained in addition to energy produced. This study is focused on investigation of effect of activated bio char for wastewater treatment processes. The char residue of coconut shell biomass (CSB) was obtained after gasification; the pyrolysis temperature was maintained between $700-1250{ }^{\circ} \mathrm{C}$. The particle size of the CSB was kept 1.4-2 mm. After a complete cycle, the CSB bio char (CSBBC) obtained was cleaned, crushed and activated using chemical activation technique. Then activated bio char was used as an adsorbent in jar test conducted with palm oil mill effluent. Fixed volume of wastewater $(300 \mathrm{~mL})$ was treated with adsorbent of varying amount i.e., 5, 10, 15, and 20 g. The results indicated the reduction in COD; 79.1\%, BOD; 85.62\% Color; 94.12\%, TDS; 82\%, TSS; $78.53 \%$ and turbidity; 96\%. CSB is readily available, more cost effective and environmental friendly than other commercially available adsorbents.
\end{abstract}

Keywords- Biomass, Bio char, Gasifier, Pyrolysis, wastewater.

Date Received: $02-10-2020$

Date Accepted: 26-10-2020

Date Published: 08-06-2021

\section{INTRODUCTION}

A ctivated carbon is widely used as an adsorbent for the purification of water and wastewater. Activated carbon is also used in a wide variety of applications which includes medical, chemical, industrial and manufacturing, and environmental remediation. Bio char provides an ideal carbon substrate source to activate and thus "designer chars" can be produced for a wide variety of applications. For the activation, a carbon source needs a high degree of micro porosity or reactive molecular sites. These are the characteristics which can give activated bio chars the ability to adsorb contaminants in soil and water. Type of feedstock, thermal conversion, and activation method are the factors that can influence the characteristics of the activated bio char.

Coconut shells, albizia and mango pit are industrial, agricultural and domestic wastes available in asian regions which can be used to produce heat and power. A variety of studies are motivated on pyro lytic bio-chars adsorption for the removal of pollutants in gas and water streams without any further treatment found by Tomlinson et al [1]. One of the major technologies to produce energy from woody biomass is thermochemical conversion. Variety of methods such as Gasification, Carbonization, Pyrolysis etc. are being applied to produce energy and some valuable by-products.

The effective utilization of biomass to produce biofuels as well as activated carbon will not only help relieve environmental problems caused by coal mining, but also lower the production cost of effective sorbents that can be used in water treatment and wastewater reclamation [4].

The main objective of this study is to compare the wastewater treatment potential of bio char obtained following pyrolysis of three biomass species as mango pit shell, coconut shell and ginisyria (gliricidia sepium).

\section{Methodology}

\section{A. Gasification process for the conversion of CSB into CSBBC}

Gasification is the conversion of biomass into combustible gas mixture by the partial oxidation of biomass at high temperature typically in the range of $800-900^{\circ} \mathrm{C}$ [3].

Pilot scale gasifier was fabricated with cyclone separator to generate producer good quality producer gas. Mango pit, coconut shell, and ginisyria were used as feed stocks [5]. Elemental analysis for CSB was performed in the laboratory to find out the properties. Figure 1 shows a schematic diagram of experimental setup with its main components.

This gasifier possesses the simplest gasifier reactor configuration. Figure 1 illustrates the updraft gasifier set up, 
where the flow of the fuel and gases are counter current. The oxidation zone lies at the bottom of the gasifier and the combustion gas passes through this zone reacting with the char and thereby releasing the required process heat [5]. Bio char collected from gasifier was activated to improve the adsorption characteristics and subsequently used for the treatment of palm oil mill effluent (POME).

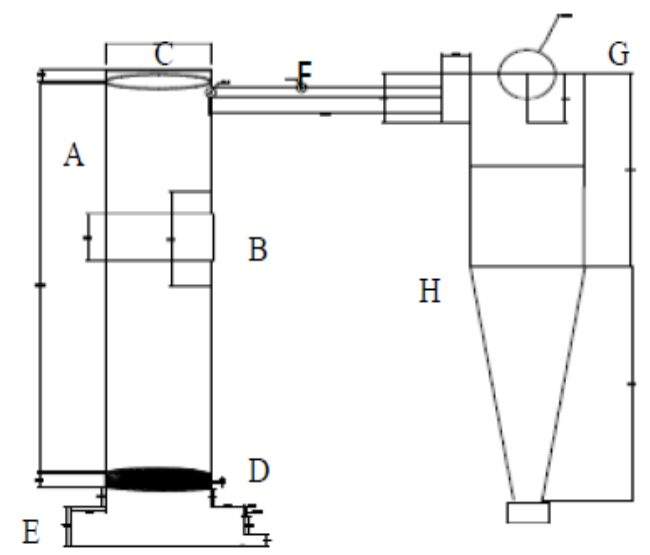

Figure 1: Updraft Gasifier with Cyclone separator. (A) Reactor; (B) Packing Plate Provision; (C) Feeding Section; (D) Grate; (E) Ash Chamber; (F) Gas Exit;(G) Sampling port;(H) Cyclone Separator (I) Fly Ash removal

\section{B. Chemical activation of CSB into Bio char (CSBBC)}

Bio char was obtained from updraft gasifier as a by-product. Grate chamber which is present at the bottom of the gasifier (Fig.1) holds the residue obtained after complete gasification process. This residue contains Bio char and the dust ash particles. The bio char obtained contains some fly ash and a small quantity of unburned material which was separated after washing with warm distilled water. Washed bio char were then oven dried and kept soaked overnight in $3 \%$ (v/v) sulphuric acid. Soaked bio char were again washed with warm distilled water thrice and kept inside oven for drying. Dried activated carbon were crushed into definite particle size ranging from 1$2 \mathrm{~mm}$ size.

\section{Wastewater characterization}

Wastewater samples were collected from local palm oil production plant present at Katubedda, Sri Lanka and characterized into its constituents as shown in Table 1.

Table 1. Characteristics of POME (after aeration process)

\begin{tabular}{lc}
\hline \multicolumn{1}{c}{ Parameter } & Value \\
\hline Color (Pt-Co) & 4140 \\
TDS (mg/l) & 5400 \\
TSS (mg/l) & 1400 \\
BOD (mg/l) & 560 \\
COD (mg/l) & 890 \\
Turbidity (FAU) & 681 \\
\hline
\end{tabular}

\section{Jar test Experiments}

CSB was selected to check its capabilities to perform as an activated carbon. Three sets of experiments were conducted using Jar test method. In the first set of experiment, equal volumes of POME $(300 \mathrm{~mL})$ were taken into beakers and prescribed amounts of adsorbent (CSBBC) were added to get the five different concentrations as 16.66, 33.33, 50, 66.66 and $83.33 \mathrm{~g} / \mathrm{Lit}$, respectively. The samples were kept in jar test apparatus and were mixed for about 1 hour at $200 \mathrm{rpm}$. After completing 1 hour cycle time, samples were kept for 40 minutes to settle sludge and other small ash particles associated with activated carbon. Finally to remove sludge and suspended ash/ carbon particles, samples obtained from jar test apparatus were passed through gravity sand filter. The product obtained was analysed for different parameters. Same procedure was repeated thrice to confirm the results.

\section{RESULT AND DISCUSSION}

CSBBC was characterized by conducting proximate and ultimate analysis and results are shown in Table 2.

Table 2. Properties of biomass feed stocks

\begin{tabular}{cc}
\hline Properties & Quantity (\%) \\
\hline Ash & 12.2 \\
VM & 84.4 \\
FC & 19.08 \\
Moisture & 10.8 \\
HHV(MJ/kg & 18.5 \\
C & 50.6 \\
$\mathrm{~N}_{2}$ & 0.83 \\
$\mathrm{H} 2$ & 5.6 \\
\hline
\end{tabular}

(VM=Volatile Matters, FC=Fixed Carbon, HHV= Higher Heating value)

Result obtained from experiments for the removal efficiency of bio char from CSBBC was observed by varying concentration and size ranging 300 micron to 550 micron. The reduction in Color (89\%) and turbidity (96\%) at the highest concentration are very high as compared to BOD (85\%), COD $(79.2 \%$,$) TDS (82 \%)$ and TSS $(79.52 \%)$. It can also be seen from Fig. 2 that the percentage reduction in pollutants has increased with increase in the concentration of adsorbent. Both coconut shell and mango pit (Fig.2 \& Fig.3) have the affinity to reduce colour and turbidity compared to other parameters

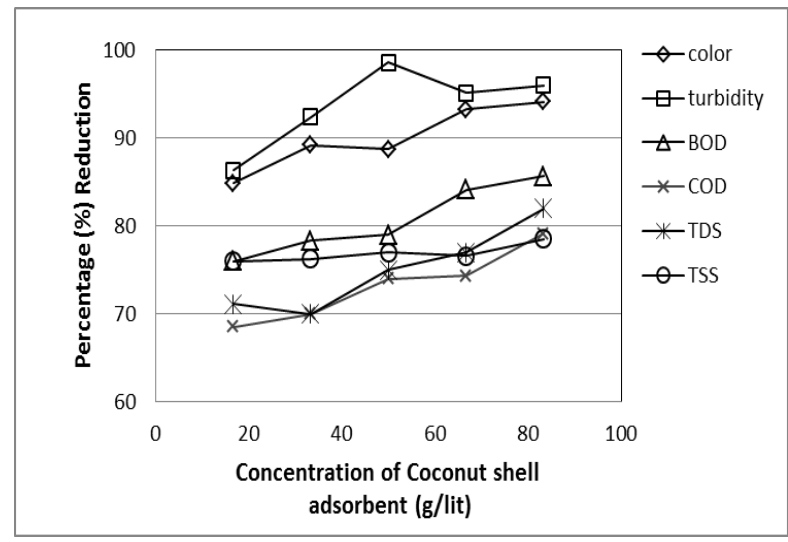

investigated.

Figure 2. Percentage reduction vs Concentration of Coconut shell adsorbent (g/lit) 
To further analyse the efficiency of the CSBBC the results were compared with previously obtained results using two different selected biomass materials. Based on the results obtained for all three biomass species, percentage reduction of turbidity is higher compared with other measured parameters. This concludes that all species can be used as better coagulants in waste water treatment processes, however the CSBBC could be

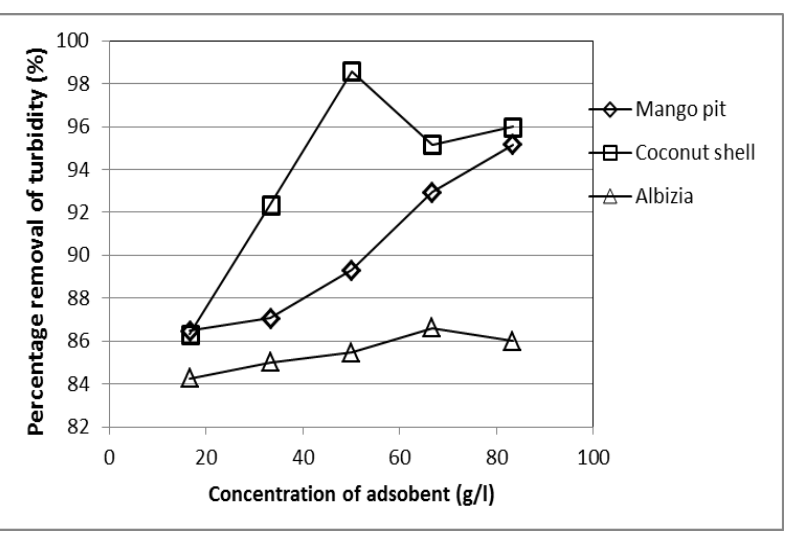

terms of percent reduction.

Figure 3.Percentage reduction of turbidity (\%) vs concentration of adsorbents $(\mathrm{g} / \mathrm{L})$

CSBBC shows the highest removal efficiency of turbidity and color compared with the other two species (Fig 3 \& Fig.4). This is due to high adsorption capacity of bio char from coconut

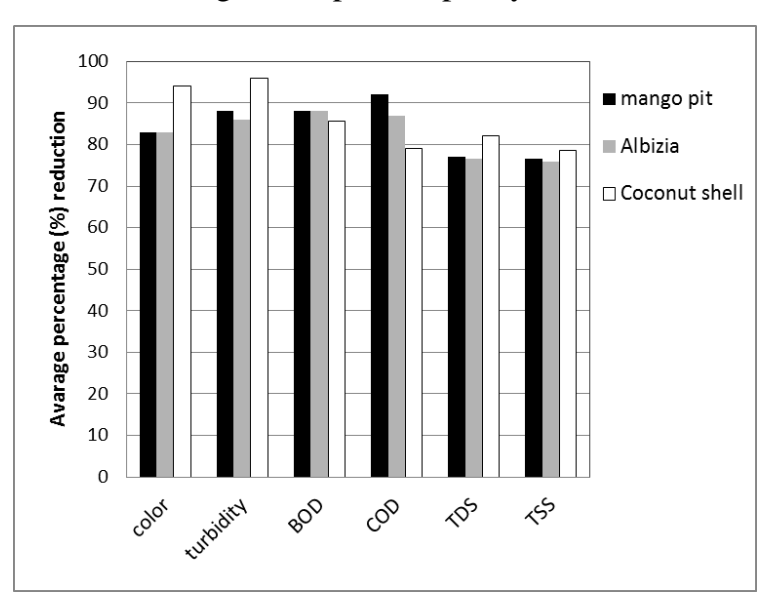

Figure 4. Average percentage reduction of Mango pit, Albizia and Coconut shell vs Color,turbidity, BOD,COD,TDS and TSS.

To compare the overall results obtained from all three adsorbants, average percentage reduction vs all measured parameters are shown in Fig.5. It can be concluded that the bio char from coconut shell shows the higher removal efficicincies for the parameters color, turbidity, TDS and TSS. Moreover, the highest COD removal efficiency is given by bio char from mango pit. Overall results indicate that the tendency of biomass adsorbent is more in terms of reduction of color and turbidity present in wastewater. However it can also be seen that the trend towards the reduction of $\mathrm{COD}$ and $\mathrm{BOD}$ are also better for all three species.

\section{CONCLUSIONS}

In addition to generation of energy from biomasses by thermal conversion, the by -product called bio char can be used as a good activated carbon for water and wastewater treatment. Bio char as activated carbon (adsorbent) not only minimizes the overall cost associated with the wastewater treatment but also minimizes the environmental issues linked to wastewater treatment as well as the amount of chemicals used. Furthermore, a variety of biomasses are used in the gasification process, which leads to generate by products such as bio char and tar besides the gases produced. Conversion of these bio char into activated carbon decreases the waste generated.

By analysing the results, It was found that with the increase in concentration of the adsorbent, the \% reduction of pollutants has increased. All bio char species showed very good coagulant properties due to the highest $\%$ reduction of turbidity. In addition all three species shows the total dissolved solids (TDS) and total suspended solids (TSS) removal efficiencies above $75 \%$.

\section{REFERENCES}

[1] M. J. Tomlinson, R. Boorman, "Production of Bio - Coal and Activated Carbon from Biomass", Foundation Design, 5th ed., Longman, Singapore, 1986.

[2] D. Mohan, A. Sarswat, Y. S. Ok, and C. U. Pittman, "Organic and inorganic contaminants removal from water with biochar, a renewable, low cost and sustainable adsorbent - A critical review," Bioresour. Technol., vol. 160, pp. 191-202, 2014.

[3] S. J. Ojolo, S. M. Abolarin, and O. Adegbenro, "Development of a Laboratory Scale Updraft Gasifier," Int. J. Manuf. Syst., 2012.

[4] J. Park, I. Hung, Z. Gan, O. J. Rojas, K. H. Lim, and S. Park, "Activated carbon from biochar: Influence of its physicochemical properties on the sorption characteristics of phenanthrene," Bioresour. Technol., 2013.

[5] M. Amin and M. Narayna, "COMPARATIVE STUDY OF ENERGY POTENTIAL OF MANGO PIT AS BIOMASS WITH COCONUT SHELL GINISYRIA \& MIXTURE IN LABORATORY SCALE DEVELOPED UPDRAFT GASIFIER,” 2015, vol. 2015, no. Rsea, pp. 299-302.

[6] http://edis.ifas.ufl.edu/ss626 "Producing bio char using a custom designed Top- lit updraft (TLUD)”., 2010.

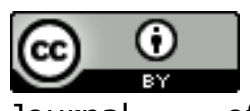

Journal of Applied and Emerging Sciences by BUITEMS is licensed under a Creative Commons Attribution 4.0 International License. 